\title{
Международные организации
}

\section{МЕЖДУНАРОДНАЯ БЕЗОПАСНОСТЬ- ПРАВО ИЛИ СИЛА?}

B. Н. Трофимов*

Как следует поддерживать международную безопасность? Добиваться заключения новых соглашений, предусматривающих частичную или полную ликвидацию вооружений, запрещающих испытания ядерного оружия и создание новых систем вооружений? Требовать присоединения всех стран к уже существуюшим соглашениям подобного рода, в частности запрешающим распространение ядерного оружия? Разрабатывать и выдвигать новые инициативные предложения для. принятия их в качестве резолюций ООН? И если это так, то цели политиков, дипломатов и юристов-международников--добиться принятия таких резолюций и заключения подобных соглашений, а также соблюдения уже существующих? А задача науки международного праванайти соответствующие аргументы и основания, чтобы убедить партнеров по переговорам согласиться с предложенными идеями? Внешне может сложиться впечатление, что борьба за международную безопасность сводится именно к таким мерам'. Так ли это?

- Видимо, оценивать роль международно-правовых средств в обеспечении международной безопасности необходимо только в общем политическом контексте этой проблемы. Каковы же хотя бы общие ее контуры?

Нужно признать, что пока далеко не все государства придерживаются единого мнения, каким образом обеспечивать глобальную международную безопасность. Попытаемся внести определенную ясность в отдельные бытуюшие в этой связи взгляды и подходы, рассмотрев подробнее следуюшие вопросы ${ }^{2}$ :

-- Велики ли возможности международного права в поддержании международной безопасности? наук.

* Сотрудник Правового департамента МИД РФ, хандидат юридических 
- Что такое «международный порядок»? Живем ли мы в сообществе или лишь в системе государств? Возрастает ли глобальная взаимозависимость государств и оправданно ли говорить о преодолении национализма?

- Существует ли реально система коллективной безопасности и совсем ли утратила свою роль система баланса сил?

- Справедлив ли тезис, что мир является высшей ценностью международного сообщества?

- Каковы оправданные рамки применения силы для обеспечения международной безопасности?

- Существует ли ясность в вопросе, какие страны и какие проблемы представляют основную угрозу для международной безопасности?

- Ведет ли разоружение к укреплению международной безопасности?

- Оружие массового уничтожения - добро или зло?

Попытаемся хотя бы в общих чертах обозначить возможные ответы на эти вопросы.

\section{Роль международного права}

Можно ли, используя какие-либо специфические международно-правовые средства, принудить другое государство к участию в междунаргдной договоренности и к ее соблюдению? Ответ на этот вопрос важен, чтобы правильно понимать роль права (точнее сказать, роль международных договоренностей, а тем более резолюций и деклараций) в контексте различных подходов к проблеме обеспечения международной безопасности.

Так что же такое-- «международное право»? Система принципов, норм и обычаев, регулирующих отношения субъектов международной системы в процессе их международного общения? ${ }^{3}$ Несомненно. Способ формально зафиксировать международную договоренность? И это верно. Важно, однако, то, что право-это метод фиксации добровольно выраженной воли различных субъектов международного права в той части, в которой эти воли совпадают, в целях облегченного или автоматического применения согласованных правил в повторяюшихся, сходных ситуациях ${ }^{4}$.

Такая государственная воля может касаться самых различных вопросов - правительственного визита, торговли, культуры, политики. Если ситуация носит повторяющийся характер, то при желании и согласии сторон вырабатывается некая абстрактная норма поведения, определяющая, как следует ве- 
сти себя в такой ситуации, какие иметь права и обязанности. Право есть формальная абстрактная оболочка, покрывающая какую-то часть таких повторяющихся либо разовых, но предполагаемых в будущем ситуаций самого различного характера. Важно, что упомянутөе согласование воль - всегда только добровольное, а в основе возникновения нормы в конечном счете лежит концепция соглашения ${ }^{5}$.

Другой важный аспект современных международных отношений - это равенство его субъектов, хотя и относительное $^{6}$. Соответственно в международных отношениях существует ограничение возможности принуждения, особенно в современную эпоху, когда применение силы стало существенно более ограниченным, чем раньше. Принуждение ограничено в отношении различных аспектов международных отношений - политических, экономических или каких-то других ${ }^{7}$. Соответственно меры принуждения не могут быть использованы в полной мере для обеспечения выполнения моральных норм, «правил игры" ${ }^{8}$ или норм международного права. Применение силы в целях принуждения, конечно, не исключено полностью, и кризис в Персидском заливе - лишнее тому подтверждение. Однако такие ситуации требуют все-таки особых обстоятельств и не являются теперь регулярным и обыденным явлением в международной жизни. Следует отметить, что в таких случаях принуждения с помощью силы, особенно вооруженной, мораль и право стоят в подчиненном к силе положении. Это утверждение не означает, конечно, что «кто силен-тот и прав», но бессмысленно отрицать, что сила применяется нередко и в неправомерных, и в аморальных целях, и подчас успешно.

Добровольность при создании и соблюдении международно-правовых норм ${ }^{9}$ и ограничение возможности принуждения (не только правового, но и морального, военного и др.) в решающей мере сокращают возможности использовать право в качестве инструмента для воздействия на позицию другого государства. На первый взгляд может показаться, что эти факторы вовсе исключают возможность такого правового воздействия ${ }^{10}$. Ведь некоторые страны позволяют себе пренебрегать даже общими принципами, например Ирак в отношении Кувейта. В других же случаях государства вполне правомерно расторгают международные договоренности, не присоединяются к уже существующим договорам и избегают участвовать в разработке новых норм, если таковые, по их мнению, противоречат их государственным интересам.

Неужели только военная сила, экономические санкции, политическое и моральное воздействие способны заставить государство-нарушителя считаться с установленным международным 
порядком? Во многом это именно так, хотя, как правило, даже просто возможность применения таких мер оказывает достаточный сдерживаюший эффект.

Что же касается международного права, то с его помощью также можно оказывать определенное воздействие, однако, видимо, только в ограниченной и достаточно специфической форме. Такое воздействие возможно в основном на ранних стадиях разработки международных договоренностей, то есть задолго до возникновения конкретной проблемы. Оно возможно, в частности, как постепенное, шаг за шагом, втягивание партнера по переговорам в определенные договоренности с помощью обоюдных компромиссов, на основе, например, баланса краткосрочных и долгосрочных интересов, с опорой при этом на более высокое качество своего долгосрочного прогнозирования ". Возможно и применение при этом морального воздействия, но в ограниченной мере, чтобы не оттолкнуть другую сторону, не дать ей повода выйти из переговоров ни на одном из этих этапов.

Только в таком виде может быть использовано международное право для внедрения той или иной внешнеполитической линия. Широковещательные инициативы, уже готовые проекты договоров, явный нажим с целью вовлечь в те или иные договоренности - все эти методы, как правило, заранее обречены на неудачу, хотя иногда приносят их авторам какойто пропагандистский успех. Бывают, конечно, ситуации, когда с такими инициативами другие государства и соглашаются. Это возможно либо в случае очевидного совпадения позиций (например, как в случае Чернобыльской аварии), либо в случае возможности легко получить какие-то односторонние преимушества. Например, если речь идет о сложных и неочевидных проблемах, в частности о разоружении. Другая сторона, скрывая свои истинные намерения, может исходить лишь из желания изменить военный паритет в свою пользу ${ }^{12}$, заплатив за это какую-то приемлемую, по ее мнению, цену, например подлержав у своего партнера по переговорам престиж миротворца.

Хороший пример утверждения в мировом сообшестве своей позиции - это переговоры по разработке Конвенции ООН по морскому праву и Соглашения о Луне. В ходе этих переговоров группа развивающихся государств смогла втянуть другие страны в обсуждение проблем НМЭП и его составной части - общего наследия человечества и постепенно добиться закрепления в обоих вышеупомянутых документах крайне выгодных ей положений. В конечном счете, правда, Соглашение о Луне не получило должного международного признания. Что же касается Конвенции ООН по морскому 
праву, то на завершаюшем этапе переговоров по ней Соединенным Штатам и некоторым их союзникам удалось из них успешно выйти, однако многие другие государства, в частности Россия, оказались втянутыми в этот процесс более основательно и до сих пор вынуждены продолжать действовать в рамках Конвенции, предпринимая при этом мучительные попытки не принимать на себя крайне обременительные обязательства.

\section{Международный порядок}

Видимо, не вызывает сомнений, что один из элементов обеспечения безопасного существования человеческого общества - это поддержание этого общества в достаточно стабильном состоянии, в условиях, позволяющих ему нормально существовать. Эта стабильность вместе с такими условиями обычно называется порядком, который не эквивалентен праву ${ }^{13}$. Для поддержания порядка внутри государства необходимо, как считают специалисты, обеспечить три фундаментальных условия:

- жизнь и здоровье граждан не должны подвергаться угрозе свыше каких-то разумных пределов;

- -договоры должны выполняться (это достаточно широкое понятие, предполагаюшее не только надежные экономические связи, но и в целом вызывающие доверие общественные отношения);

- имущественные права не должны подвергаться сомнению сверх разумных пределов.

Эти три условия обычно кратко формулируются как «жизнь», «правда» и «имущество»"

Для сообщества государств порядок может означать сохранение системы и сообщества государств, сохранение независимости или суверенитета отдельных государств, поддержание мира, выполнение международных обязательств и защиту вышеупомянутых общечеловеческих ценностей: жизни, правды и собственности.

Система государств и сообшество государств-это также не одно и то же. Существование сообщества предполагает, что государства связаны порядком, чувством общих интересов в элементарных целях, в то время как система может означать, что государства связаны только, например, балансом сил. Система государств характеризуется плюрализмом их суверенитетов и степенью их взаимодействия, преврацающего их в систему. Степень их согласия с общими правилами и институтами характеризует их уже как сообщество. 
Как же обеспечивать стабильность государственных суверенитетов и выполнение обязательств? Обычно высказывается мнение, что в современный период эти цели во многом достигаются за счет системы коллективной безопасности ${ }^{15}$, действующей главным образом через механизм ООН. Иными словами, при этом предполагается, что большинство государств искренне выступает за международный порядок, мир, справедливость. Когда же какие-либо страны действуют вопреки этому, то остальное международное сообщество (координируя свои действия в рамках ООН) должно принимать меры против нарушителя - вплоть до экономических санкций или даже военных акций. При этом активную роль в принятии решений играет Совет Безопасности, опирающийся на принцип единогласия великих держав. Считается также, что система коллективной безопасности заменила систему баланса сил, действовавшую до этого несколько столетий. Соответственно если сейчас и упоминается баланс сил, то нередко лишь в контексте военного или экономического паритета, но не как механизм поддержания международного порядка ${ }^{16}$.

По мнению автора, система поддержания международной безопасности в послевоенный период действует несколько иначе ${ }^{17}$, опираясь главным образом как раз на систему баланса сил. Ясность в этом вопросе важна, так как в том случае, если теория не будет соответствовать реальному положению вещей, хотя бы даже частично, вряд ли на ее основе удастся принимать систематичные меры по обеспечению международной безопасности. Отдельная же страна, придерживающаяся такой не вполне адекватной теории, не будет играть соответствующей ее положению роли в решении проблем международной безопасности, а принимаемые ею меры могут привести лишь к неоправданным материальным расходам (например, из-за ошибочных направлений оказания военной и экономической помощи другим странам и таких же ошибочных направлений развития собственной армии) и уж никак не будут способствовать укреплению ее международного престижа.

Как представляется, в послевоенный период в международной политике закрепилось одно широко распространенное заблуждение, а именно предположение, что бопышинство стран готово терпеть даже определенную несправедливость ради сохранения мира и недопущения новой мировой войны. Желаемое принималось за действительное. Конечно, на формирование таких взглядов в 40-50-е годы оказали воздействие вполне объективные обстоятельства. Международное сообшество все еще находилось под впечатлением итогов второй мировой войны. Существовавшие тогда государства в своем подавляющем большинстве всемерно и искренне стремились пред- 
принять коллективные усилия, чтобы не допустить повторения военной трагедии. Достаточно легко была создана ООН, находили подлержку многие из инициатив, направленных на нормализацию международной жизни. Казалось, что все страны стремились создать гармоничное, справедливое и, главное, безопасное сообщество государств. Нужно признать, что эти настроения до сих пор во многом сохранились в промышленно развитых странах, участвовавших во второй мировой войне,Японии, Западной Европы, Северной Америки. Рост различных взаимосвязей между пими послужил основой для разработки теории взаимозависимости ${ }^{18}$, утверждающей, что эпоха межгосударственного противостояния во многом преодолена. Наверное, это достаточно обоснованное утверждение, но, к сожалению, в основном лишь применительно к вышеупомянутым странам.

На международной арене в послевоенный период появилась многочисленная группа государств, возникших в результате крушения колониальной системы. Нужно признать, что они, в отличие от развитых стран Запада, в большинстве случаев поставили в центр своих концепций устройства мира несколько иные ценности, обусловленные низким уровнем экономического и социального развития. Постоянная угроза голода, нищета стали серьезными дестабилизирующими факторами внутригосударственной жизни и не могли не найти отражения во внешней политике, одним из главных направлений которой стала борьба за справедливость.

К сожалению, порядок, мир и справедливость бывают иногда взаимоисключающими понятиями.

Специфическая позиция развивающихся государств трансформировалась и в их несколько обособленное положение в международных отношениях. Акцент на собственные интересы привел к усилению националистического начала, а также, вероятно, к относительному ослаблению процессов роста международной взаимозависимости.

Тут нужно упомянуть, по крайней мере, три концепции, по-разному описываюшие феномен системы или сообщества государств. Концепция, предложенная Т. Гоббсом, предполагает, что все государства имеют только свои интересы и соблюдают между собой «правила игры» только вынужденно. Если за правилом не стоит сила, то оно не может ограничивать государство. Естественным состоянием такой системы является война. Согласно концепции И. Канта, международное сообщество является всеобщим единством отдельных личностей, связанных общими интересами вне зависимости от государственных границ. Наконец, концепция Г. Гроция описывает систему государств как международное сообщество этих 
государств с общими интересами, отличными от интересов отдельных личностей ${ }^{19}$. Современное сообщество государств, по мнению большйнтва специалистов, соответствует скорее представлениям Г. Гроция. Однако, как кажется, в современном обществе можно найти признаки и двух других концепций. В противостоянии идеологий порядка и взаимозависимости, с одной стороны, и справедливости и национализма-с другой, проявились, видимо, в большей мере признаки концепции Гоббса.

Специфические внешнеполитические установки стран «третьего мира», социалистических стран, явления растущего национализма сказались на механизме функционирования сообщества государств, сделали.невозможным глобальное использование системы коллективной безопасности. Коллективность оказалась невозможной, так как не только отдельные государства, но и целые их группы стали исходить из различных, не всегда совпадаюших между собой международных ценностей.

Какие же механизмы поддержания международной безопасности действуют сейчас в этом до определенной степени разделенном сообществе государств? Так, несомненно, что в послевоенный период достигнуто значительное число международных договоренностей, принято много деклараций и заявлений (совместных и односторонних), создано немало соответствующих международных органов и проведено достаточно много международных форумов, касающихся вопросов поддержания международной безопасности.

Какова роль этих документов в поддержании международной безопасности? В соответствии с ними государства принимают обязательства не применять силу при решении международных проблем, сохранять мир, сокращать свои вооружения, ограничивать их разработку, испытания и распространение среди третьих стран. Иными словами, речь идет как раз об уже рассмотренной нами ситуации в отношении международного права - обязательства принимаются добровольно и соблюдаются только добровольно, а если заинтересованность в этом отсутствует, то могут быть нарушены даже и общие принципы международного права.

Как же обстоит дело с вопросом, например, о неприменении силы? В идеальном случае государство обладает правом на самооборону, а агрессор должен быть наказан в соответствии с Уставом ООН. В этой связи можно привести следуюший, далеко не полный перечень грубых нарушений международного права: агрессия Англии, Франции и Израиля против Египта в 1956 году, интервенция США в Ливане и Иордании в 1958 году, агрессия Бельгии в Конго, интервенция США 
против.Кубы в 1961 году (залив Свиней), вмешательство США во внутренние дела Лаоса, вооруженная интервенция США в Доминиканской Республике в 1965 году, агрессия Израиля против арабских государств в 1967 году, агрессивная война CUIA против Вьетнама, «футбольная» война между Гондурасом и Сальвадором в 1969 году, война между Индией и Пакистаном в 1971 году, участие советских войск в войне в Афганистане, вторжение США на Гренаду в 1983 году, участие вьетнамской армии в боевых действиях на территории Кампучии, война между Ираком и Ираном из-за разграничения территории по реке Шатт-эль-Араб, бомбардировка Соединенными Штатами Ливии в 1985 году, минирование США никарагуанских портов в 1984 году, нападение Ирака на Кувейт в 1990 году, югославские события и многочисленные конфликты на территории бывшего СССР.

Как нетрудно заметить, в последние 40 лет слова нередко расходились с делами (причем в каждом таком случае обязательно находилось какое-либо формальное оправдание). Тем не менее мир пока не оказался ввергнутым в третью мировую войну. Случайность ли это? Может быть, именно многочисленные декларации, обязательства и соглашения играют сдерживающую роль? Несомненно играют, однако, как показывают вышеприведенные примеры, пределы такого сдерживания достаточно ограничены 20 .

Можно предложить следующее возможное объяснение, почему мир пока не втянулся в череду непрерывных вооруженных конфликтов. Во-первых, потому, что крупнейшие государства намерены не допускать подобного развития событий, и, во-вторых, потому, что именно они обладают пока реальной силой, чтобы обеспечить свое намерение.

Как же конкретно реализуется этот механизм намерений, опирающихся на силу? Представляется в этой связи полезным рассмотреть концепцию баланса сил ${ }^{21}$, которой длительное время успешно пользовались в международных отношения ${ }^{22}$. Конечно, баланс сил в настоящее время приобрел одну новую черту. Поскольку в международном сообществе появились явные военные и экономические лидеры, сушествовавший ранее баланс сил коалиций государств оказался замененным балансом сил сверхдержав. Видимо, этот механизм в основном и действует сейчас, объективно поддерживая международную безопасность и существуя вне зависимости от того, признают его или нет отдельные страны ${ }^{23}$.

При существующем балансе сил главным приоритетом международных отношений является поддержание порядка, а не соблюдение такого этического принципа, как справедливость (или поддержание мира). 
Система баланса сил не лишена, конечно, недостатков и подвергается в этой связи достаточно серьезной критике. Весь вопрос заключается в том, можно ли предложить какуюлибо иную, столь же эффективную систему поддержания порядка. Наверное, можно разрушить систему баланса сил, но если это в конце концов произойдет, то вряд ли так же надежно удастся подлерживать порядок и мир, если вообще это будет возможно. Критики системы баланса сил нередко указывали, что она сводит международное поведение государств к погоне за силой, к политике силы, влечет за собой пренебрежительное отношение к международному праву, в конечном счете не способствует поддержанию порядка, так как попытки сохранения баланса являются источником войн, а если порядок и поддерживается, то в интересах сверхдержав за счет малых государств.

Действительно, система баланса сил предполагает возможность локальных войн, но ее цель - это не поддержание мира во всех случаях и любой ценой, а сохранение системы государств как таковой.

Ведущую роль в современной системе баланса сил играют сверхдержавы, которые считаются в основном только с интересами друг друга, в чем-то друг другу уступают, но в любом случае считаются с интересами малых стран в меньшей мере. Тем не менее баланс сил предполагает независимость не только больших, но и малых государств. Баланс сил между сверхдержавами-это все-таки, видимо, и условие существования международного права. Если бы вместо баланса существовало, например, подавляющее преимущество одной сверхдержавы ${ }^{24}$, то трудно представить себе механизм, который заставлял бы ее считаться с правом. В этой связи уместно привести мнение Л. Оппенгейма: «Первейшая и принципиальная мораль, которая может быть извлечена из истории развития права государств,- это то, что право наций может существовать только если есть равновесие сил между членами сообщества наций» ${ }^{25}$. Вместе с тем на практике интересы сохранения баланса могут вызывать иногда нарушения международного права, то есть интересы сохранения порядка в итоге господствуют над интересами соблюдения права.

Необходимо отметить, что некоторые аспекты современных международных отношений могут быть объяснены не только системой баланса сил, но часто и так называемой этическо-политической системой ${ }^{26}$. Она предполагает, что центральные приоритеты в международных отношениях отдаются этическим и политическим ценностям, которых придерживается какая-то страна, не обязательно при зтом являющаяся 
сверхдержавой. Такая страна делит все остальные государства на сторонников и не сторонников своего подхода, считая первых друзьями, а вторых - противниками. В результате такое государство стремится помогать своим «друзьям» и находится в состоянии, по меньшей мере, идеологической войны со своими «противниками», не отвергая возможности и военного столкновения. В конечном же счете такая система также ведет к отрицанию этических принципов, таких, в частности, как справедливость, мир и порядок.

Отношения между СССР и США всегда являлись хорошим примером комбинации двух систем. С одной стороны, СССР и CIIIA избегали прямой конфронтации, стремились к поддержанию глобального правопорядка, но, с другой стороны, находились в состоянии постоянной идеологической борьбы, в угоду которой приносились подчас весьма серьезные жертвы.

Какова же в таком случае роль $\mathrm{OOH}$, если коллективная безопасность-это больше декларация, чем реальность? Этот форум позволяет на регулярной основе осушествлять международные контакты государственных деятелей, декларировать те или иные политические задачи, организовьпать в их поддержку международное сообщество. ООН способствует мирному урегулированию споров, координирует многочисленные международные программы, даже иногда использует под своей эгидой войска, например для разведения конфликтующих сторон ${ }^{27}$. Правда, войска ООН использовались в Корее и в Конго. Однако это был, наверное, первый и последний опыт подобного рода по насильственному военному урегулированию проблемы коллективными усилиями в рамках этой организации. Война в Персидском заливе внесла, кажется, окончательную ясность в вопрос о значении ООН. Она фактически лишь санкционировала неминуемое применение силы (кстати сказать, коллективное) против Ирака. Подобные же коллективные акции проводились и в других регионdх, например против Гренады, однако в этом случае уже даже без санкции со стороны $\mathrm{OOH}$.

Следует указать, что американские политологи исходят, как правило, из необходимости и оправданности применения силы в более широких пределах, чем это предусмотрено пунктом 4 статьи 2 и статьей 51 Устава ООН. По существу, можно говорить, что США проводят такую государственную политику. Так, доктрина Рейгана является отражением подхода так называемых «неореалистов», считаюших, в частности, что система коллективной безопасности, заложенная в Уставе ООН, оказалась нежизнеспособной ${ }^{28}$. 


\section{Кто представляет угрозу для международной безопасности?}

Особенности внешнеполитических интересов различных групп государств сказываются и на формировании источников угрозы для международной безопасности. Что касается взглядов, высказывавшихся по этому поводу в СССР (как политиками, так и военными), то они сводились чаще всего к следующему. Основная угроза для международной безопасности происходит из военного противостояния сверхдержав-СССР и США, что определяется как уровнем развития вооруженных сил, так и принципиальными различиями идеологического плана ${ }^{29}$. Соответственно необходимо готовиться к возможному вооруженному столкновению именно с этим противником, к обороне на случай нападения ${ }^{30}$. Отсюда - усилия советской стороны, направленные на достижение паритета в вооружениях, причем особенно в количественном плане.

Западные специалисты придерживаются, однако, несколько иной точки зрения. Они чаще всего исходят из того, что международная безопасность во многом поддерживается именно системой баланса сил сверхдержав, важнейший элемент которой - это их противостояние, но не конфликт. Существенно, что западные политологи проводят в этой связи принципиальную границу между враждебностью и войной, считая, что даже самое серьезное охлаждение отношений с СССР означало только враждебность. Соответственно строилась и военная политика западных сверхдержав, во многом предполагавшая возможное вооруженное противостояние с СССР только в косвенной форме и в третьих странах ${ }^{31}$.

В данной статье в силу ее ограниченного размера этот вопрос излагается в самом общем виде, схематично, лишь для того, чтобы обозначить обшие контуры системы международной безопасности. Естественно, можно привести целый ряд фактов, говорящих о готовности США вести войну и с СССР,--огромный арсенал стратегических вооружений, конкретные военные планы, такие как «Троян», «Дропшот», «Хафмун» 32 . В этой связи можно высказать следующее суждение. Конечно, огромные материальные возможности позволяли США быть готовыми к любым вариантам развития военного конфликта, что, в сущности, понятно, учитывая их неуверенность в реальных намерениях бывшего СССР, который готовил свои вооруженные силы к войне именно с США.

Конечно, война может возникнуть в силу случайности, из-за несанкционированного использования ядерного оружия, из-за сбоя в работе компьютеров оборонного комплекса и т. д. 
Тем не менее шанс такого развития событий пока чрезвычайно мал. По сути дела, за весь послевоенный период подобной случайной ситуации не складывалось ни разу.

Военные действия могут возникнуть и в силу многих таких причин, которые порой даже трудно предвидеть. Достаточно "спомнить «футбольную» войну между Сальвадором и Гон.урасом. Однако по-прежнему наиболее велики шансы вооруженных конфликтов и из-за территорий и ресурсов. ПО сути дела, эта причина является (и долгое время являлась) наиболее частой при возникновении войн, а грядущее широкомасштабное освоение Мирового океана и Антарктики может стать новым источником конфликтов, особенно учитывая отсутствие четкой теории правового режима подобных пространств общего пользования ${ }^{33}$.

Представляется, однако, целесообразным исследовать более подробно, какие именно группы стран наиболее склонны к неправомерному использованию силы при решении международных проблем. Вопрос о сверхдержавах был уже кратко рассмотрен выше. Особый же интерес представляют страны с нестабильной внутриполитической обстановкой. К таким странам оправданно отнести болынинство развиваюцихся государств, а теперь и некоторые страны на территории бывшего СССР. Именно в них в силу давления больших социальных групп,-доведенных подчас до отчаяния голодом и нищетой, наиболее вероятны международные военные авантюры. Национализм этих стран, помноженный на идеологические и религиозные догматы, тоталитарность внутриполитического устройства некоторых из них, достаточно широкое распространение в «третьем мире» современных видов обычных вооружений, а также оружия массового уничтожения, огромная внешняя задолженность создают в перспективе крайне опасную для всего мира ситуацию ${ }^{34}$. Кстати сказать, речь тут может идти не только об опасности войны, но и о серьезной экологической угрозе, так как желание всемерно ускорить экономический рост при одновременном дефиците материальных и финансовых ресурсов, а также квалифицированных кадров нередко ведет к тому, что местные власти смотрят «сквозь пальцы» на развитие на своей территории экологически опасных производств. Трагедия в Бхопале показала это вполне ясно.

Если исходить из того, что развивающиеся страны и государства на территории бывшего СССР могут в перспективе стать основным источником опасных ситуаций,-то следует, видимо, сделать особый акцент на разработку концепции взаимоотношений с ними России. Задачи в военной области тут, вероятно, в общих чертах понятны: не допускать распространения таких видов оружия, которые могут привести 
к расширению конфликта, а тем более к глобальной катастрофе; ясно определить для себя, связана ли та или иная опасная ситуация в этих странах с противостоянием сверхдержав или нет, и, учитывая существуюшую при этом принципиальную разницу, вести соответствующую линию в каждом из этих случаев, поддерживая «способности вооруженных сил быстро и эффективно воздействовать на возникаюшие в мире конфликты и кризисы».

В политическом плане важна позиция по отношению к выдвигаемым «группой 77» концепциям переустройства международных отношений, главным образом к попыткам установить НМЭП. Эти идеи реализовываются пока в форме вполне конкретных международных документов - резолюций различных международных организаций, и особенно резолюций Генассамблеи $\mathrm{OOH}$, и некоторых уже упоминавшихся международных соглашений - Конвенции ООН по морскому праву 1982 года и Соглашения о Луне 1979 года. Основное направление этих попыток - добиться международной справедливости, причем в таком виде, как это понимается самими развивающимися странами, то есть даже ценой нарушения международного порядка. Порождаемая при этом напряженность в международных отношениях чревата весьма серьезными конфликтами, затрагивающими жизненные интересы широкого круга стран. Проблема решается сейчас в форме борьбы за те или иные конкретные кридические формулировки. Именно тут сейчас определяется, удастся ли найти общеприемлемые компромиссы или своекорыстно понимаемая справедливость будет насаждаться даже в ущерб порядку ${ }^{35}$.

\section{Разоружение}

Хотя проблема разоружения носит в основном политический, а не международно-правовой характер, тем не менее представляется полезным затронуть в самом общем плане и ее, поскольку она нередко рассматривается как ключевой элемент обеспечения международной безопасности и как реальный путь к обеспечению всеобщего мира ${ }^{36}$. По сути дела, можно даже говорить о государственной политике России с таким содержанием. Так ли, однако, этот тезис бесспорен? Совершенно ли несомненно, что ликвидация основных орудий насилия приведет к гармонизации отношений в человеческом обществе? Тут можно высказать следующие сомнения.

Во-первых, история человечества показывает, что можно уничтожить целые народы и с помощью самых примитивных 
видов оружия, хотя, конечно, современное оружие намного более эффективно в этом отношении.

Во-вторых, если признать, что система баланса сил попрежнему действует и сверхдержавы играют решающую роль в поддержании международного порядка, опираясь на свои вооруженные силы, то тогда придется также признать, что существенное разоружение может вести к разрушению уже существующего и пока эффективного механизма по поддержанию международной безопасности с надеждой создать в будущем нечто, его заменяющее.

В-третьих, в ряде развитых стран в ближайшие десятилетия будут созданы так называемые гибкие производства. Это позволит достаточно быстро переналадить промышленные мощности для производства современного оружия, причем в значительных количествах. Что означает в таких условиях идея всеобщего разоружения, выдвинутая, кстати сказать, именно Советским Союзом? ${ }^{37}$

В-четвертых, совершенно несомненно, что оружие массового уничтожения является также крайне мощным средством сдерживания ${ }^{38}$, способствующим поддержанию не столько порядка, сколько ядерного мира. Оправданно ли отказываться от этого?

B-пятых, насколько в условиях растущего национализма можно реально рассчитывать, что все государства добровольно согласятся разоружиться? События в Персидском заливе показывают, что это вряд ли достижимо средствами морального и политического воздействия. Вообще, реально ли рассчитывать начать разоружение не с России и СШIA, a, например, с Ирака и Израиля? ${ }^{39}$

Изложенные в данной статье соображения подводят, по мнению автора, к необходимости серьезно переосмыслить ситуацию, складываюшуюся в современном мире в области поддержания международной безопасности, и внести весьма существенные коррективы в соответствующие внешнеполитические концепции нашего государства. В реальной действительности в международных отношениях явно сформировалась целая группа двойных стандартов. С одной стороны, публично провозглашаются идеи коллективной безопасности, неприменения силы, ориентации на механизмы, предусмотренные Уставом ООН. С другой стороны, ряд развитых государств все более открыто прибегают даже к применению вооруженной и невооруженной силы для решения международных проблем. 
При этом важно, что под такие действия подводится концептуальная база, причем не только на национальном, но и на межгосударственном уровне. По сути дела, мы становимся свидетелями формирования нового «современного международного права цивилизованных народов", альтернативного уже существующему международному праву. При существующей расстановке сил на международной арене и с учетом нашей внутренней ситуации для России было бы правильнее не столько противиться этому, сколько быстрее и эффективнее принять новые правила игры.

1 Точки зрения по этому вопросу см. Мюллерсон Р. А. Роль и возможности международного права в создании ВСМБ// Всеобъемлюшая система международной безопасности и международное право.-М., 1987.-С. 8-9; Рыбаков Ю. М. Правовые аспекты обеспечения ВСМБ и развитие международного сотрудничества // Всеобъемлющая система международной безопасности и международное право.-С. 5-6; Ушаков Н. А. ВСМБ и прогрессивное развитие международного права // Там же.--С. 15.

2 Подробнее эти вопросы см. Трофимов В. Н. Военная и экологическая безопасность. Международное право и сила.-М., 1991. C. 4.

${ }^{3}$ Международное право (под ред. Н. Т. Блатовой).-М., 1987.--

${ }^{4}$ Курс международного права (в семи томах).-- Т. 1.- М., 1989.C. $184-189$.

${ }^{5}$ См. Вступительная статья Г. И. Тункина к кн.: Э. Х. де Аречага. Современное международное .право.--М., 1983.-С. 10-12; Колосов Ю. М. К вопросу о примате международного права // Международное право в современном мире.-- М., 1991.-С. 7.

6 Тункин Г. И. Право и сила в международной системе.--М., 1983. - C. $27-28$.

7 Что касается методов принуждеңия, то некоторые юристы выделяют такие из них, как дипломатические (включая угрозу применения силы), идеологические, военные и экономические (McDougal M., Feliciano F. Law and Minimum World Public Order.- Yale, 1961.P. $28-31$ ).

${ }^{8}$ Hoffmann S. Ethics and Rules of the Game Between the Superpowers // Right v. Might. International Law and the Use of Force.N.Y., L., 1989.--P. 72--76.

9 См. также Курс международного права (в семи томах).- Т. 4.M., 1990.-C. $74-84$.

10 Можно привести в качестве примера концепцию ориентированного на политику международного права, согласно которой право перестает быть системой обязательных норм, становясь лишь элементом политики. См. McDougal M. International Law. Power and Policy // Recueil des cours de l'Academie de droit international.-- Vol. 82 (1953).P. 169; McDougal M., Feliciano F. Op. cit.-- P. 7; Falk R. The Role of Law in World Society: Present Crisis and Future Prospects// Toward World 
Order and Human Dignity. Essays in Honor of M. McDougal.- N.Y., 1976.-P. 150; Barcun M. International Norms as Facts and Ideals // ASIL. Proceedings of the 66th Annual Meetings.-1972.-P. 41.

${ }^{11}$ Craig G. A., George A. L. Force and Statecraft. Diplomatic Problems of Our Time.- N.Y., 1983.-P. 157-171.

12 Мотивы, оправдывающие нарушение паритета, могут быть самыми различными. См., например, Моисеев М. Проблемы безопасности: необходим взвешенный подход// Известия.- 1991.-5 anp.

${ }^{13}$ Сушествует значительное различие между понятиями «порядок" и «правопорядок». О том, что такое «правопорядок», см. Курс международного права (в семи томах).- - Т. 4.-- С. 161.

${ }^{14}$ Bull H. The Anarchical Society. A Study of Order in World Politics.-L., 1979.- P. 4-5.

i5 Международную безопасность, обеспечиваемую совместными усилиями государств в мировом или региональном масштабе, принято называть коллективной безопасностью. См. Дипломатический словарь (в трех томах).- T. I.-M., 1986.- С. 190.

16 Серьезные сомнения в эффективности системы коллективной безопасности высказывались уже достаточно давно (см. Morgenthau H. J. Politics Among Nations. The Struggle for Power and Peace.- N.Y., 1950.-P. 232).

${ }_{17}$ См. в этой связи Hoffmann S. Op. cit.-P. 74-75. См. также Aron R. Peace and War.-N.Y., 1966; Morgenthau H. J. Op. cit.-P. $125-166,270-286$.

${ }^{18}$ Keohane R. O., Nye J. S. Power and Independence. World Politics in Transition.-Boston, 1977; Brown L. R. World Without Borders: The Independence of Nations.- N.Y., 1972.

19 Bull H. Op. cit. - P. 24-27.

20 Один из последних примеров - это намерение СIIA применить в Сальвадоре силу, причем даже вопреки недавней советско-американской договоренности по этому вопросу. См. Чародеев Г. А. А как же советско-американское заявление? // Известия.-1991.-13 апр.

21 Система баланса сил определяется нередко как состояние, когда ни одно государство не может абсолютно доминировать и диктовать право другим (Wattel de E. Droit des Gens. bk III.- ch.ii.- section 47). Моргентау определял баланс сил как четыре возможных состояния: 1) политика, направленная на достижение определенных целей; 2) реальное положение вещей; 3) примерно равное распределение сил; 4) любое распределение сил (Morgenthau H. J. Op. cit.-P. 125, note 1).

${ }_{22}$ Сушествуют, конечно, различные концепции, описываюшие современную систему поддержания международной безопасности и отличающиеся от концепции баланса сил или коллективной безопасности. См., например, "A New National Partnership" (speech by Secretary of State Henry A. Kissinger at Los Angeles.- 1975, Jan. 24.-New release. Department of State. Bureau of Public Affairs).

${ }^{23}$ См., например, Богданов Р., Кортунов А. О балансе сил // Международная жизнь.- 1989.-- № 7.- С. 3-15.

${ }_{24} \mathrm{~A}$ не происходит ли сейчас именно такое смещение баланса в пользу CWIA? См., например, сообщение о заявлении Р. Чейни (Известия.- 1991.-10 апр.).

is Oppenheim L. International Law.- Vol. I.-L., 1905.-P. 73. 
CM. например, Hofimann S. Op. cit.-P. 74-75. Этим же вопросам посвящены и другие работы: Aron R. Op. cit.; Morgenthau H. J. Op. cit.

27 О снижении роли ООН см., например, Эитин М. Л. Через укрепление ООН к демократизации и упрочению международного правопорядка //Международное право в современном мире.-М., 1991.-C. $120-135$.

28 Подробнее о взглядах американских ученых на вопросы применения силы см., например, Scheffer D. J. Introduction: the Great Debate of the 1980s//Right v. Might. International Law and the Use of Force. Council on Foreign Relations Press.-- N.Y., L., 1989.- P. 3-13.

29 Стратегия спасения человечества. XXVII сьезд КПСС и борьба 32 мip.-M., 1987.-C. $63-124$.

30 Моксеев М. Указ. соч. О связи военной доктрины и советской модели обеспечения международной безопасности см. Ивапапепко Л. А. Формирование новой модели обеспечения военной безопасности // Международное право в современном мире.- М., 1991.C. $10-19$.

31 Gaddis J. L. The Long Peace. International Security.-- Vol. 40.No 4 (Spring 1986).- P. 119.

32 Карганов С. Бомба и президент // Новое время.- 1988.- № 5.C. 41 .

33 Трофимов В. Н. Правовой статус Антарктики.- М., 1990.C. $26-62$.

34 Глобалыные проблемы современности.-М., 1981.- С. 78-79.

35 Bull H. Op. cit.-P. 122-125; Henkin L. How Nations Behave. Law and Foreign Policy.- N.Y., 1979.- P. 127.

${ }_{36}$ См. Курс международного права (в семи томах).- Т. 4.C. $191-201$. Кроме того, политика разоружения нередко ассоциируется с политикой сокращ тия расходов на вооружения, что на самом деле совсем не одно и т', же.

37 League of Nations. Conference for the Reduction and Limitation of Armaments. Verbatim Records of Plenary Meetings.- Vol. I.- P. 82.

38 Богданов Р., Кортунов А. УКаз. соч.-C. 3-15; Gray C. Deterrence and Strategic Defense: A Positive View // Disarmament and Security. 1987 Yearbook.- Moscow, 1988. - P. $571-572$.

39 «я же критикую мечту Горбачева не за то, что она нежелательна, а за то, что ее осуществление невозможно в обозримом будущем. Больше того, соглашение о ликвидации всего ядерного оружия при сущеструющих политических и технических реальностях могло бы, как эт - ни парадоксально, увеличить риск возникновения ядерной войны» (Макнамара Р. От ошибок к катастрофе: как выжить в первый ядерный век. Раздел «Горбачев: ликвидировать все ядерное оружие».-М., 1987.- С. 73). 